\title{
USING ARCHETYPES TO CREATE USER PANELS FOR USABILITY STUDIES: STREAMLINING FOCUS GROUPS AND USER STUDIES
}

\author{
K. Stavrakos , S. Ahmed-Kristensen, T. Goldman
}

\section{Keywords: comfort, anthropometry, ergonomics, archetypes}

\section{Introduction}

Design engineers who are involved in the early conceptual phase of the development of products such as seats, headphones and domestic appliances stress the increasing importance of comfort. Comfort is taken into account in the purchasing decisions of buying a chair, a bed, and when driving a car, or flying. Industry strives to produce products that are comfortable in order to increase the appeal to consumers. The Second European Survey on Working Conditions [Merllie, et al. 2002] that took place in 1996, where a sample of 1000 workers from each member state were interviewed, revealed that back pain (30\% of the workers) and muscular pains in arms or legs (17\% of workers) were amongst the most common work-related health problems. Absenteeism due to work-related health problems affects $23 \%$ of workers each year (averaging out at 4 working days lost per worker). These health problems strongly relate to postural musculoskeletal discomfort. Hence, designers need to increase their knowledge on both comfort and discomfort in product design (and workspaces).

The terms comfort and discomfort are widely used in studies where prototypes are tested for usability. Despite the frequent use of these terms there is an absence of a general notion of comfort or discomfort. There are three main issues when designing a product to achieve comfort: 1) the exact cause of comfort is unknown, 2) comfort relies to a certain extent on subjectivity and, 3) there is a lack of a methodology for considering comfort in the design process [Vink 2005]. Extensive research mainly in the form of comfort studies [Kuijt-Evers 2004 ; DeLooze et al. 2003] has explored some of the influential factors of comfort such as postural stress [Kee et al. 2012], levels of pressure and force increase [Goossens, et al., 2002] and noise [Vink et al. 2001]. Most of these factors are physical, physiological or linked to external attributes of the environment in which the interaction between a human and a product takes place. For products that are in a physical contact with the human body, such as chairs and hand tools, researchers have attempted to match product dimensions with people's anthropometry [Mououdi, et al. 1997; Cho 1994]. However, there is little research for external ear products, such as headphones and headsets with respect to human ear dimensions, partially due to the limited data sets available. In terms of methods to benchmark human dimensions against product dimensions, research is scarce regarding the evaluation of the ergonomic functionality of products. This translates into two issues: primarily current comfort studies either give no justification for the selection of the number of users to include in the comfort studies, or select small samples of users for prototype benchmarking [Parcells et al. 1999 ; Gouvalli et al. 2005] which are not representative of the population as a whole; and secondly there is a lack of methodology to define product dimensions and predict good fit. Essentially, the research presented in this paper, responds to the call for a new approach towards comfort and draws inspiration from Vink [2012] who has stressed the need for an improved comfort methodology.

Given this background, the main aim of this research is to propose a methodology to develop a reliable user panel for the execution of comfort studies in the industry of external ear-worn products, by using archetypes to represent large clusters of anthropometric data. The subaims were to investigate and generate the proposed methodology through a second usability study comparing archetypes' responses to a number of participants' responses.

This paper consists of four main parts: 1) The paper first reviews the existing literature on definitions of comfort and the studies attempting to link comfort to anthropometry; 2) Then it presents, in detail, the main stages of the archetype methodology, i.e. the process to select participants and the cluster analysis 
to generate the archetypes; 3) The framework of the ARCH method and the results of the validation of the archetypes are presented in the findings section; and 4) The paper concludes with a discussion of the theoretical and industrial implications of the archetypes and the archetypes methodology (ARCH), as well as, the limitations and the contributions of the methodology.

\section{Literature Review}

\subsection{The concept of comfort}

This section will introduce comfort definitions. In dictionaries comfort is described as "a subjective state of well-being in relation to an induced environment including mechanical vibration or shock". Comfort is, however, commonly associated with terms such as, "assistance, relief, support" and is also seen as "a feeling of freedom from worry or disappointment" [The Oxford Dictionary of English 2005]. Slater [1987] defines comfort as a pleasant state of physiological, psychological and physical harmony between a human being and the environment. Richards [1980] states that comfort is the state of a person that involves a sense of subjective well-being in reaction to an environment or a situation. In regards to the subjective nature of comfort Vink [2005] states that comfort is a subjective experience: For a passenger on a long distance flight, back discomfort is of great importance whereas another passenger wants a reduction in noise or more space. In this paper, comfort is defined as (1) a construct of subjectively defined by one's personal nature, (2) as a reaction to the environment and (3) is affected by factors of various natures (physical, psychological and physiological) [Vink 2005]. The focus of this paper is on the physical dimension of comfort.

\subsection{A debate in the literature: comfort versus discomfort}

\subsubsection{Comfort and discomfort as points in a continuum scale}

Comfort has been linked to the term "discomfort" since the first attempt to operationally define comfort as "the absence of discomfort" [Hertzberg 1958]. Comfort is not a well-defined concept yielding an ongoing debate in the literature. The debate stresses the difference between comfort and discomfort. Several researchers [Hertzberg 1958 ; Richards 1980 ; Bishu et al. 1981] seem to be making a distinction between two different states of comfort. According to Bishu et al. [1981], in particular for seating design, "the goal of the designers is to reach the state of absence of discomfort, where the working individual is oblivious of the fact that he or she is seated." In his study, Richards [1980] has suggested that the fact that people rate their subjective responses across the entire continuum from discomfort to comfort indicates that comfort is part of a bipolar dimension that can be attributed to characteristics of design. This statement is supported by a number of papers in hand tool evaluation studies in which comfort is measured in terms of discomfort [Chao et al. 2000 ; Fellows et al. 1991]. For hand tools, comfort is primarily determined by functionality and the physical interaction between the user and the product. As discomfort factors are present in hand tool use, the perception of comfort may be dominated by that of discomfort. [Kuijt - Evers et al. 2004]. In their study, Kuijt-Evers et al. [2004] identified factors having the closest relationship to comfort among 40 descriptors, such as a good fit in the hand, functional, easy to use, reliable, etc. These factors were clustered. The statistical analysis distinguished 6 comfort factors as significant: (1) Functionality; (2) Posture and muscles; (3) Irritation and pain of hand and fingers; (4) Irritation of hand surface; (5) Handle characteristics; And (6) aesthetics. These factors explain $53.8 \%$ of the variance. In the use of hand tools the same descriptors relate to both comfort and discomfort.

Two studies in the design of seats also support the use of the same descriptors for both comfort and discomfort: [Jianghong et al. 1994] for the passenger seat for a new type of bus and [Wilder et al. 1994] to compare two different track seats (with and without suspension) when changing driving postures. It was concluded that comfort and discomfort can be seen as two opposites on a continuous scale. This stems from the fact, that people frequently and naturally distinguish ordered levels of their subjective responses across the entire continuum from strongly positive to strongly negative [Richards 1980]. The same principle underlies the graded scales [Habsburg, et al. 1977] that have been used to evaluate seats, in which issues of functionality and usability are raised. 


\subsubsection{A division of discontinuity between comfort and discomfort}

Opposing the theory of seeing comfort and discomfort as two extreme states on a continuous scale ranging from extreme discomfort through a neutral state to extreme comfort, several studies have questioned the intuitive assumption of understanding comfort/ discomfort as a single dimension on a continuous scale. These studies [Kleeman 1981; Zhang et al. 1996] argue that comfort and discomfort are affected by distinctly different variables, and assessment of comfort and discomfort should be based on different types of criteria. In the study by Zhang et al. [1996], the identification of these variables was the primary goal. A total of 104 respondents provided descriptors of the feelings they experienced when they felt comfortable (e.g. agreeable, at ease, calm) or uncomfortable (e.g. fatigue, cramped, restless) in a seated workplace. From this study, 43 descriptors emerged, which were grouped into two main factors, which were interpreted as comfort and discomfort. Feelings of discomfort are mainly associated with pain, tiredness, soreness and numbness. Comfort, on the other hand, is associated with feelings of relaxation and well-being [Paul et al. 1997]. The theory of Helander and Zhang [1996] described in this paragraph convinced the authors of this paper that there was a division or discontinuity between comfort and discomfort scales, that is, sitting comfort and discomfort were independent entities associated with different factors: discomfort is related to biomechanics and fatigue factors whereas comfort is related to a sense of well-being and aesthetics. It can be argued that comfort and discomfort need to be treated as different and complementary entities in ergonomic investigations.

\subsection{Anthropometry and comfort: the challenge of fitting the tasks to the human}

A challenge for design engineers and comfort specialists who work at the early stages of the development of products that are in physical contact with the human body is to define a set of human factors in order to achieve high physical comfort. Defining these factors will enable designers to predict physical factors of comfort such as good fit in the ear, for example in the case of wearing a Bluetooth device.

Anthropometry is considered the ergonomic core of any attempt to resolve the dilemma of fitting the tasks to the human [Sanders et al. 1993]. To highlight the relationship between comfort and fit a comfort model often cited with respect to product comfort, that is, the model by De Looze et al. [2003], is presented here, see Figure 1. The model shows a relationship between physical product feature experiences with respect to discomfort and comfort. In the comfort model shown in Figure 1, different factors underlying sitting discomfort and comfort are described, as well as the relationships among these factors. Confirming the discontinuity of discomfort and comfort, the left side of this theoretical model concerns discomfort. The physical processes, which underlie discomfort, refer primarily to the exposure of the individual to the interaction with a physical product. This exposure is initiated by the physical contact between the human body and the product. Hence the notion of good fit and the manner of how the product rests on the human body is a strong evaluative term for short-term physical comfort, that is for human-product interactions which last for 2-3 minutes. 


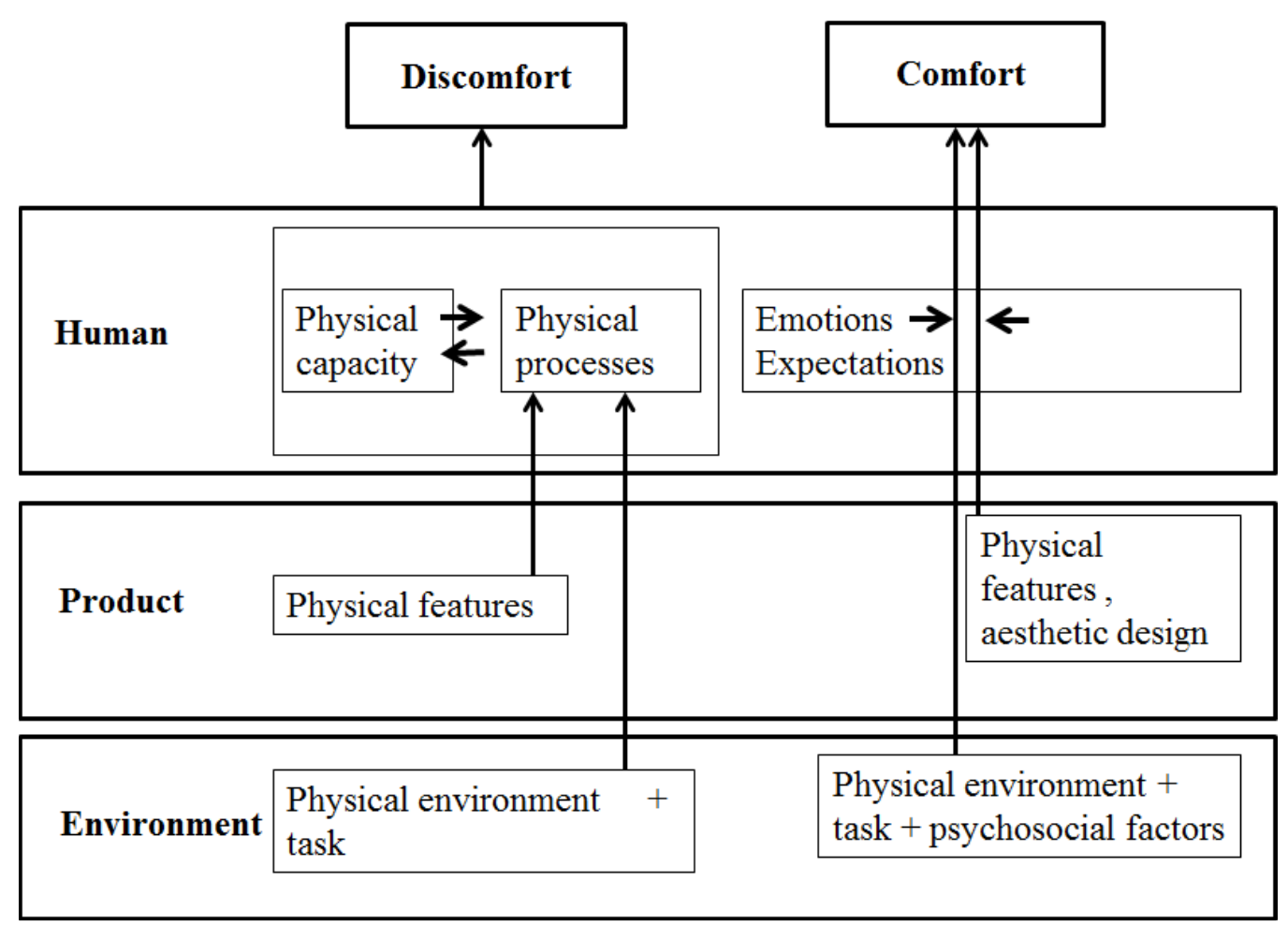

Figure 1. The comfort model for sitting, described by De Looze et al. [2003]

In regards to external ear products such as bluetooth headsets and headphones good fit is a crucial physical factor of comfort to ensure the success of these products. Designers require anthropometric data to identify human factors and inform design decisions with respect to external ear devices. Current approaches are restricted in the presentation of of anthropometric data only [Jung et al. 2001 ; Klamklaya 2008]. The collection of ear data includes the use of various measurement instruments. Jung et al. [2001] provided anthropometric dimensions of ears of Korean subjects using digital calipers. Other methods suggest the use of simple geometric calculations to acquire dimensions from a 2D photograph by setting reference points before taking the photographs. In regards to data collection of other body parts, such as head and legs, other relatively noninvasive, 3D imaging techniques are applied. These include various forms of stereophotogrammetry [Weinberg et al. 2006], topography techniques [Ghoddousi et al. 2006] and surface scanning technologies [Hennessy et al. 2002].

In other disciplines such as seating design, design engineers have attempted to design desks and chairs based on anthropometric data [Hibaru et al. 1994 ; Parcells et al. 1999]. Parcells et al. [1999] studied the mismatch between furniture and students' dimensions by measuring anthropometric characteristics of American children aged 11-13 years and the dimensions of their classrooms' desks and chairs, reporting that only $18.9 \%$ of students could find an appropriate match [Gouvali et al. 2005]. Other studies provide detailed anthropometric data and some of them also offer recommendations for design [Klamklaya 2008].

The majority of these studies [Jung et al. 2001 ; Hibaru et al. 1994] focus on the acquiring of anthropometric data, and this is limited to physical fit, however no studies were found that propose methodologies to define the user group and focus groups to test the products for user studies. In particular for the providers of technology for in - ear use products, there appears to be a lack of definition of a reliable user panel and a validated methodological framework to link ear anthropometry to design. A large number of participants is needed in order to build a reliable user group to represent large populations. The building of archetypes, that is, a user panel of people who could represent large populations from an anthropometric point of view, will allow the selection of a smaller group of persons 
for user and focus groups, which will save time and resourses, whilst being more representative of the data, rarther than selecting the participants for the focus groups in random.

Given this background, the two hypotheses of this research are presented here:

H1: Archetypes can be used to represent large populations and therefore streamline focus groups.

$\mathrm{H} 2$ : The perception of good fit can be predicted based on the use of archetypes.

Based on the notion of the archetypes and the validation of the hupotheses, a methodological framework will be developed.

\section{Methods}

A main study was carried out to validate the first hypothesis. The study generated archetypes from a dataset of 200 participants and a second study was executed to evaluate the data from the archetypes with 20 participants and, hence, validate the proposed $\mathrm{ARCH}$ methodology. This section presents the various steps of the ARCH methodology as well as the second evaluative study with respect to the set of two hypotheses presented earlier.

\subsection{First Hypothesis - Is it possible to use archetypes to represent large populations?}

To test the first hypothesis (H1: Is it possible to use archetypes to represent large populations and therefore streamline focus groups?), a study was executed using an in-the-ear bluetooth headset at an early prototype phase. The actual prototype cannot be presented in this paper due to confidentiality reasons. However, the 3D printed headset resembled in shape and form to the product depicted in Figure 2.

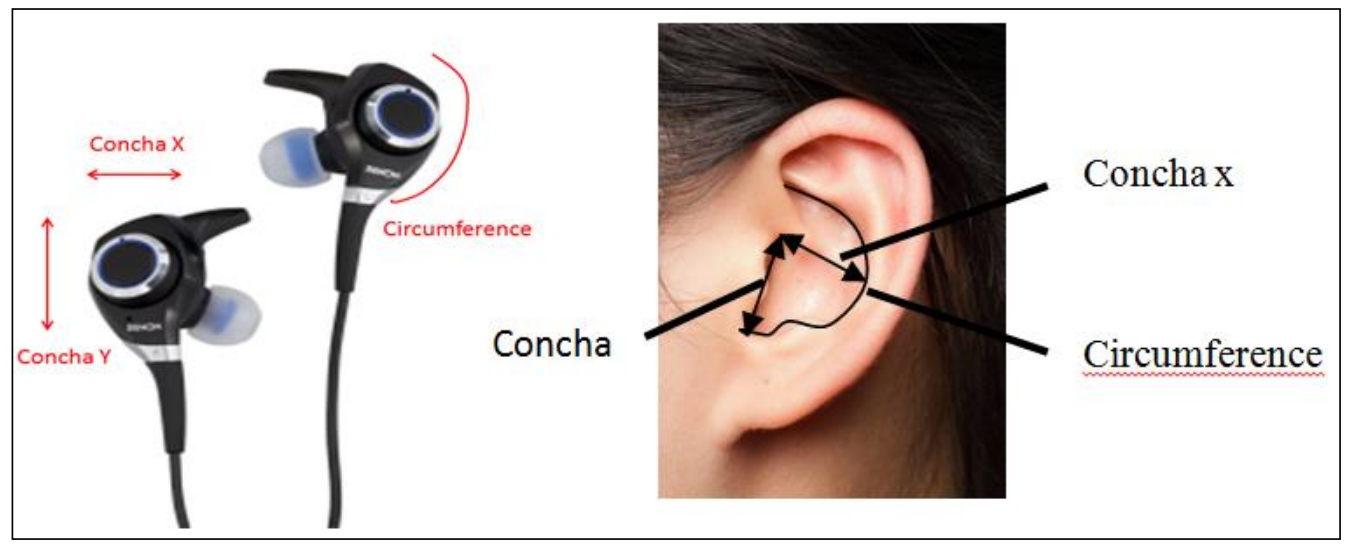

Figure 2. An image of the prototype and respective critical ear dimensions

Anthropometric data of ear dimensions were collected to represent the population of Denmark (= $5,500,000$ people). The calculation of the sample size was executed with the use of the following mathematical equation to assess the number of participants needed to reach in order to accomodate for reliable representation of the Danish population. The Cochran's formula for categorical data was applied:

$$
\text { Necessary Sample Size }=\left[(\mathrm{Z}-\mathrm{score})^{2} * \operatorname{StdDev}^{*}(1-\mathrm{StdDev})\right] /\left[(\text { margin of error })^{2}\right]
$$

,where $\mathrm{n} 0$ is the sample size, $\mathrm{z}$ is the confidence level (set to 1,96 for a $95 \%$ confidence), $\mathrm{p}$ is the estimated proportion of an attribute that is present in the population (chosen to be 0.5 which is the worst case scenario) and $\mathrm{c}$ is the confidence interval (Cochran 1977).

In the case of Denmark, the sample size required is 196 people for a confidence level of $95 \%$, confidence interval $=7$ and population size $=5,500,00$ people. Hence, a randomized sample of 200 Danish people (100 men, 100 women) was chosen with ages ranging from 22 to 67 years to match the requirements of 
the calculated sample size. For the Danish population, a number of 6 critical ear dimensions were defined and measured for both left and right ears of the 200 participants (see Table 1). The linear dimensions (ear length, ear breadth, ear height, concha $\mathrm{x}$ and Concha $\mathrm{y}$ ) were acquired with the use of a vernier caliper. The non-linear dimension (ear circumference) was acquired with the use of an elastic silicon tube that was positioned along the ear circumference curve, as shown in the right image in Figure 3. In total 2,400 linear and non-linear ear measurements were collected.

\begin{tabular}{|c|c|c|c|c|c|c|c|c|c|c|}
\hline & \multicolumn{4}{|c|}{ Participants } & \multicolumn{6}{|c|}{ Left Ear } \\
\hline & Surname Name & Gender & Age & Height & Ear Length & Ear Breadth & Ear Height & Concha $\mathrm{X}$ & Concha Y & Circumference \\
\hline 1 & & $\mathrm{M}$ & 39 & 189 & 63,24 & 33,82 & 23,41 & 22,82 & 18,1 & 54,24 \\
\hline 2 & & $\mathrm{M}$ & 28 & 180 & 64,67 & 29,86 & 17,95 & 20,16 & 16,97 & 54,54 \\
\hline 3 & & $\mathrm{M}$ & 45 & 180 & 65,16 & 32,87 & 23,04 & 19,1 & 16,68 & 56,87 \\
\hline 4 & & M & 41 & 190 & 59,79 & 26,72 & 20,28 & 18,14 & 18,25 & 53,11 \\
\hline . & & . & . & . & . & . & . & . & . & . \\
\hline . & & . & . & . & . & . & . & . & . & . \\
\hline . & & . & . & . & . & . & . & . & . & . \\
\hline 200 & & $F$ & 32 & 172 & 71,44 & 25,39 & 11,6 & 18,1 & 19,9 & 49,84 \\
\hline
\end{tabular}

Table 1. Part of the collected ear data

\subsection{Description of the main study: generation of archetypes and cluster analysis}

Three critical ear dimensions were chosen out of the six measured based on the areas of physical contact between the prototype and the human ear (see Figure 2). These were the Concha X, Concha Y and Circumference (Left ear). The data were clustered using the Ward's minimum variance method, which identifies the pair of clusters that leads to minimum increase in total within-cluster variance after merging the clusters. This increase is a weighted squared distance between cluster centers. The 200 participants were clustered based on the three selected ear dimensions. Hence, the data of ears were clustered in 9 meaningful groups. Table 1 shows an example of how the clusters were formed (of 2 out of 9 clusters). The numbers (also see first column from the left in Table 1) indicate the participants (out of 200) belonging to the clusters.

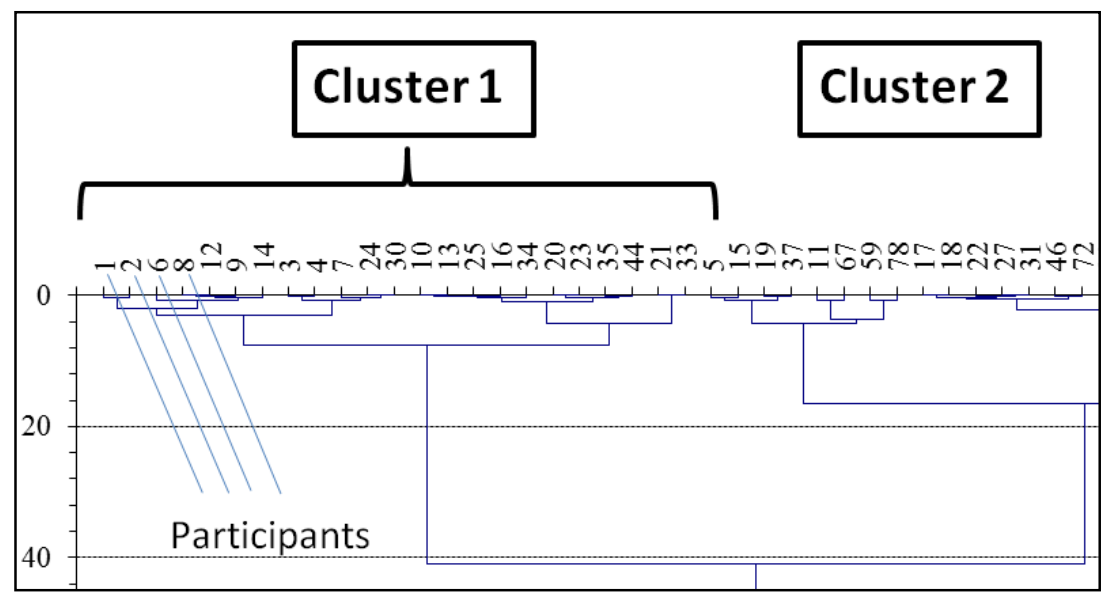

Figure 3. Part of the 9 groups - clusters as derived from Ward's minimum variance method

As shown in Figure 3, each group contained roughly $15-25$ participants. To identify a representative person for each of the clusters developed, a deeper observation of the data was executed. In the next step frequency diagrams were made for each ear dimension in each group as shown in Figure 4 for Concha X, Group 1. This resulted in 3 frequency diagrams for each of the three ear dimensions within each group. By developing the frequency diagrams, it was possible to separate the data into smaller intervals and assess which interval each of the cluster members' dimensions belonged to. 


\begin{tabular}{|c|c|c|c|c|}
\hline & & \multicolumn{3}{|c|}{ Bin Limits } \\
\hline MIN & 12,27 & 0 & 12,27 & 1 \\
\hline MAX & 17,61 & 1 & 13,03 & 0 \\
\hline AVG & 15,85 & 2 & 13,80 & 0 \\
\hline & 0,763 & 3 & 14,56 & 2 \\
\hline & & 4 & 15,32 & 2 \\
\hline & & 5 & 16,08 & 1 \\
\hline & & 6 & 16,85 & 7 \\
\hline & & 7 & 17,61 & 3 \\
\hline \hline
\end{tabular}

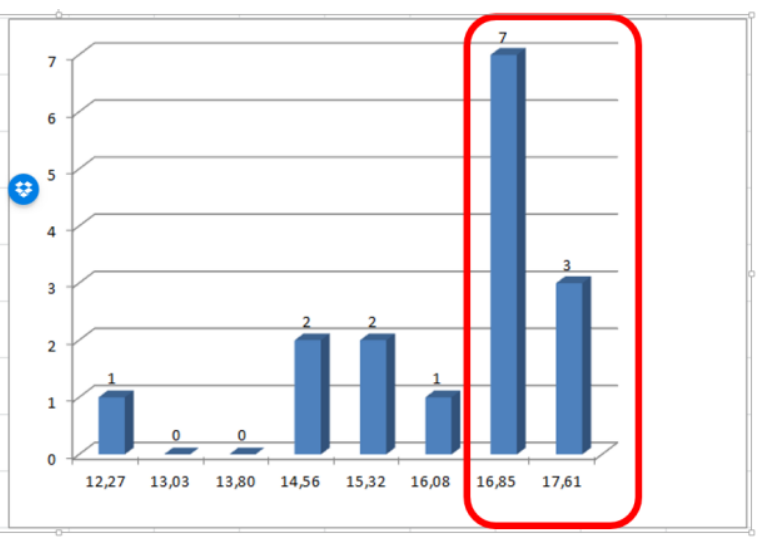

Figure 4. Frequency diagrams for concha X, Group 1

Popular intervals were chosen to include at least $60 \%$ of the cluster members within each cluster. In the case of Concha $X$ in Figure 4 these intervals were interval 6 and 7. By investigating all three frequency diagrams regarding our selected critical dimensions, Concha X. Concha Y and Ear Circumference, the archetype person was then selected based on which person belonged in all three popular intervals for all the three dimensions.

\subsection{Second Hypothesis - Is it possible to predict the perception of good fit based on the use of archetypes?}

To test the second hypothesis, (H2: Is it possible to predict the perception of good fit based on the use of archetypes?), the same dataset of the 200 participants was used. Among them 20 participants were randomly chosen from all 9 clusters which were generated previously using cluster analysis. These 20 participants along with the 9 archetype persons (who were defined in the previous study) participated in an empirical study where they interacted with two groups of three external - ear products. Each of the participants interacted with 3 different external headsets out of a possible 6, see Figure 5. All participants were asked whether they were familiar with the products that were tested in advance, in order to avoid bias towards one or more products. All participants were unfamiliar with the products they interacted with. During the interaction the researcher placed the products upon the subjects' ears, hence the users were unable to see the products. The participants were not blindfolded, in order to minimize intrusiveness. 

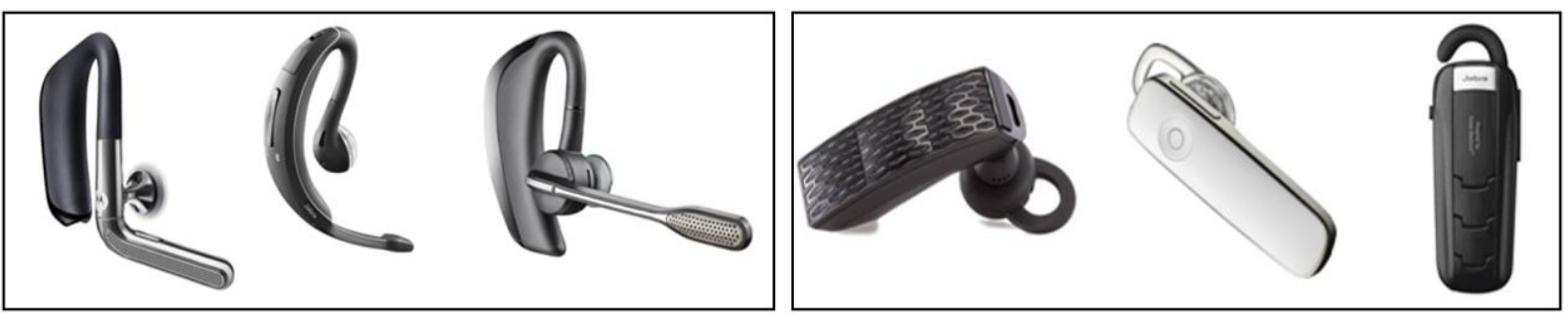

Figure 5. The groups of behind - the - ear and in - the - ear bluetooth headsets

Data for this study were collected with a questionnaire consisting of a question on physical fit. The question was given in a 24 point double sided form. The participants were asked to evaluate the products in terms of good fit, see figure 6.

1. Please describe the level of secure fit you experience towards the product by drawing a circle $(\mathrm{O})$ on the desired line in the following comfort scale:

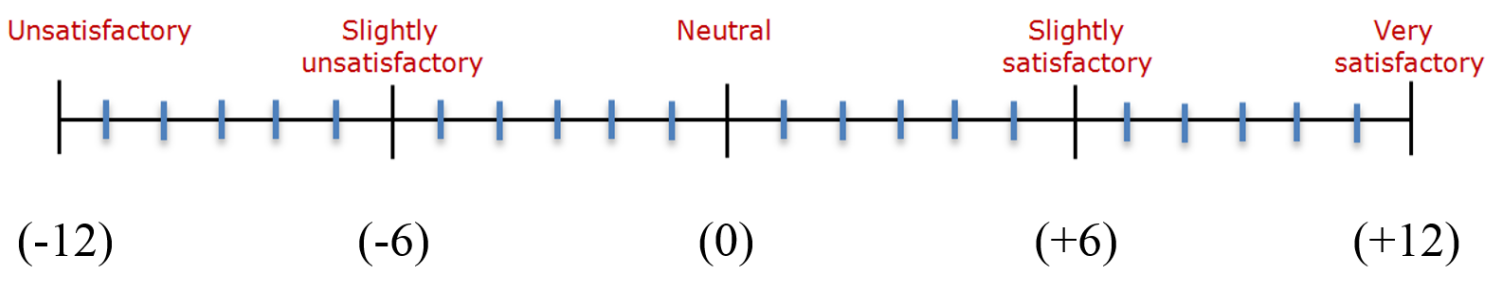

Figure 6. Semantic scale and attributed scores for physical fit

There were a total of 9 archetypes representing 9 clusters. The archetype person's scores were benchmarked against the respective scores of the participants who belonged in the same cluster. The deviations between the responses of the 20 participants against the responses of the 9 archetypes were calculated and compared to each other to understand if the archetype could represent the cluster (group of participants) from which the archetype belonged.

\section{Findings and discussion}

The following section consists of two parts. The first part presents the ARCH framework which is a visulaised summarisation of the different steps of the execution of the first study to generate the archetypes. The second part presents the findings of the second study to evaluate the archetypes.

\subsection{Designing a comfort study to evaluate products based on a reliable user panel}

Based on the description of the first study the following methodological framework (the ARCH method) to create a reliable representative user panel of a large population is proposed, see Figure 7. In the same figure, the example of executing the methodology is shown, as it was described in the above sections. The method is dependent on the attributes of the product, hence the product definition precedes most of the phases of the framework to ensure that these are identified early on and used to create the correct clusters and select the appropriate archetype. Once the product is defined it is necessary to execute preliminary interactions involving users in order to identify the critical dimensions which fully describe the respective interaction between the human and the product. This will provide a reliable set of critical product dimensions that highlight the anthropometric data that need to be collected. Once the archetypes have been defined these can be used in two ways. The first way is to use the archetype people's dimensions in order to design comfort studies where the researcher could make inquiries on physical properties of comfort towards the design and improvement of new prototypes. However, the authors would like to underline the importance of selecting prototypes with similar attributes (e.g. similar manner of use, similar geometry, etc) to the product used at the beginning of the method in order to 
ensure the validity of the archetypes. The second way is to define test panels based on the generated archetypes. These panels can be used for both quantitative and qualitative studies.

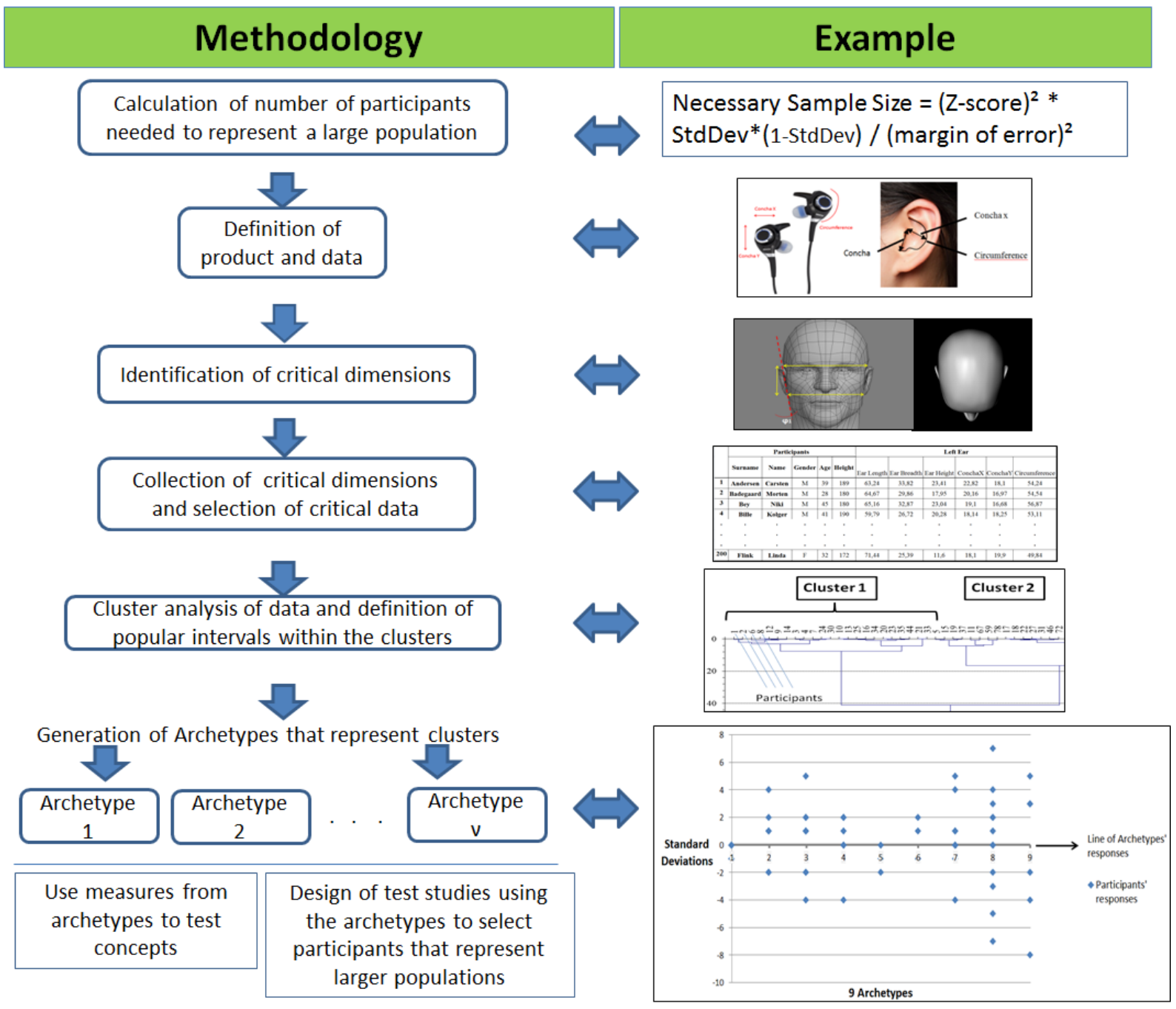

Figure 7. Proposed methodological framework (ARCH) to represent large populations

\subsection{Predicting physical comfort based on the notion of archetypes}

In this section it is shown that physical factors of comfort can be predicted based on the notion of archetypes. In total, 29 people participated in the questionnaire including the 9 archetype people. The participants scored their fit factor, that is, how securely the product is placed on the ear, during their interaction with the 3 bluetooth headsets. As shown in Table 2 each of the participants was categorised to his or her cluster from a total of 9 clusters derived from the 200 participants based upon the ear dimensions. A condition for the validity of the study was that each participant and the archetype from the same cluster interacted with the same group of products. Therefore care was taken to ensure that this was the case. Hence, the responses of the participants could be compared against the responses of the archetype person. Once the responses were retrieved the deviations of the participants' responses were calculated against their archetypes' responses. In total they were a total of 60 datapoints ( 3 per person) compared to 27 datapoints ( 9 archetype persons x 3 products). See Table 2. 


\begin{tabular}{|l|l|l|l|l|l|l|l|l|l|l|}
\hline & & & & & & & & & $\begin{array}{c}\text { Total } \\
\text { Number of } \\
\text { responses }\end{array}$ \\
\hline $\begin{array}{l}\text { 9 Archetype } \\
\text { people }\end{array}$ & 1st & 2nd & 3rd & 4th & 5th & 6th & 7th & 8th & 9th & $\begin{array}{c}\text { 9 People } \mathbf{3} 3 \\
\text { Products }= \\
\text { 27 responses }\end{array}$ \\
\hline $\begin{array}{l}\mathbf{2 0} \text { Participants } \\
\text { Product }\end{array}$ & 2 & 1 & 3 & 4 & 2 & 1 & 3 & 3 & 1 & $\begin{array}{l}\mathbf{2 0} \text { People x 3 } \\
\text { products }=60 \\
\text { responses }\end{array}$ \\
\hline $\begin{array}{l}\text { Produ (In-the } \\
\text { ear } \\
\text { Behind-the- } \\
\text { ear) }\end{array}$ & $\begin{array}{l}\text { the } \\
\text { ear }\end{array}$ & $\begin{array}{l}\text { Behind } \\
\text { the ear }\end{array}$ & $\begin{array}{l}\text { In } \\
\text { the } \\
\text { ear }\end{array}$ & $\begin{array}{l}\text { Behind } \\
\text { the ear }\end{array}$ & $\begin{array}{l}\text { Behind } \\
\text { the ear }\end{array}$ & $\begin{array}{l}\text { In } \\
\text { the } \\
\text { ear }\end{array}$ & $\begin{array}{l}\text { Behind } \\
\text { the ear }\end{array}$ & $\begin{array}{l}\text { In } \\
\text { the } \\
\text { ear }\end{array}$ & $\begin{array}{l}\text { Behind } \\
\text { the ear }\end{array}$ & \\
\hline
\end{tabular}

Table 2. Distribution of participants to the 9 clusters

As shown in Figure 8, the deviations of the 20 participants were plotted against the scores of their archetypes. Not all 60 points can be seen clearly in the graph, due to overlapping of points with similar responses. The zero $\mathrm{x}$ axis is called the line of archetypes and it represents the responses of the archetypes (ArchRes). Each of the 60 points in the graph represents the deviation of the participant of the same cluster response (PartResp) against the archetype response (ArchRes). Hence, each point represents the mathematical difference (ArchRes - PartRes). A close deviation, would mean that the answers of the cluster members were almost similar to the archetypes', indicating that the archetypes can indeed represent their group. If all the points are as close to the horizontal axis as possible this would indicate a close match of the participants' response to that of the archetype.

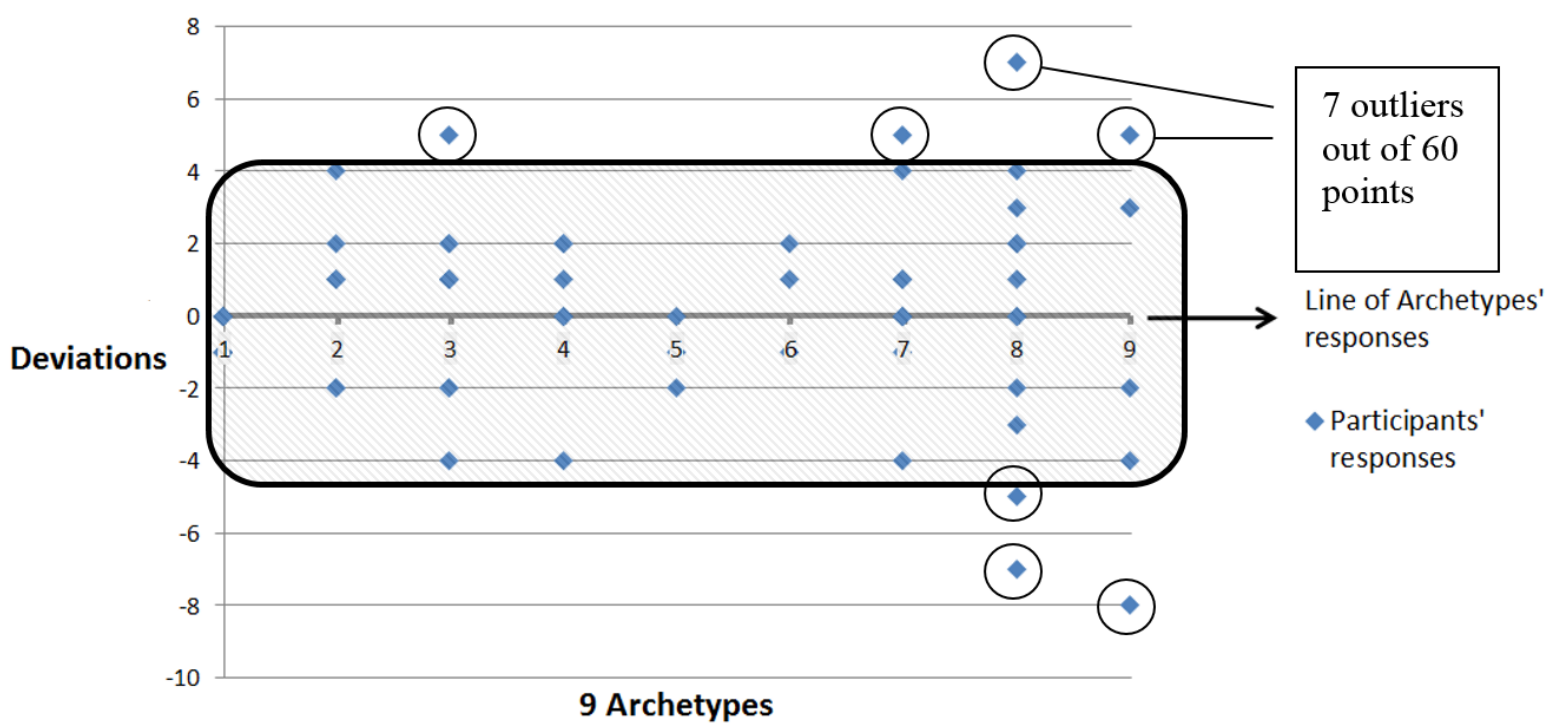

Figure 8. The chart of deviations

The scale of the deviations on the y axis follows the attributed scores of a 24 point scale, from the question on physical fit which was presented earlier, that is, from -12 to +12 . An area of closeness to the archetypes' responses for each of the cluster member's response was defined as -4 to +4 (the area is shown in Figure 8) assuming that the mathematical difference (ArchRes - PartRes) which regards to 24-scaled questions would indicate that the archetype person's and the cluster member's responses are aligned. With the exception of 7 responses (out of a total of 60) close deviations are observed. This indicates that it is possible to predict people's perceptions of physical properties of comfort based on 
anthropometric data, through the use of clusters and archetypes as representatives of these clusters. This finding forms a link between perception and human factors and can be seen in this instance as a prediction of the users' perception of fit based on the anthropometric properties of the archetypes that represent them. For the archetypes 7 and 9, where a larger deviation is observed the second group of the behind-the-ear products was used for the interaction with the participants. The use of these products may have been the reason for wider deviations since these products have different attributes to the prototypes upon which the archetypes were developed. These attributes concern product geometry, the manner of wearing the product, etc and this issue is elaborated upon in the section of the limitations of the study.

\subsubsection{Statistical Justification of Closeness}

The statistical closeness of the archetypes' responses to the cluster members' responses was assessed. This was realized by calculating the measure of the Root Mean Square Deviation (RMSD) or Root Mean Square Error (RMSE). The RMSE of a model prediction with respect to the estimated variable $X_{\text {mod }}$, which for this study, is the Archetype person's response $\left(X_{\text {clus }}\right)$, is defined as the square root of the mean squared error:

$$
R M S E=\sqrt{\frac{\sum_{i=1}^{n}\left(X_{o b s, i}-X_{\mathrm{mod}, i}\right)^{2}}{n}}
$$

where $X_{o b s}$ is observed values, which for this study are represented by the cluster members' responses $\left(\mathrm{X}_{\text {clus }}\right)$. The RMSE was calculated across the clusters for each archetype, as shown in Figure 9,

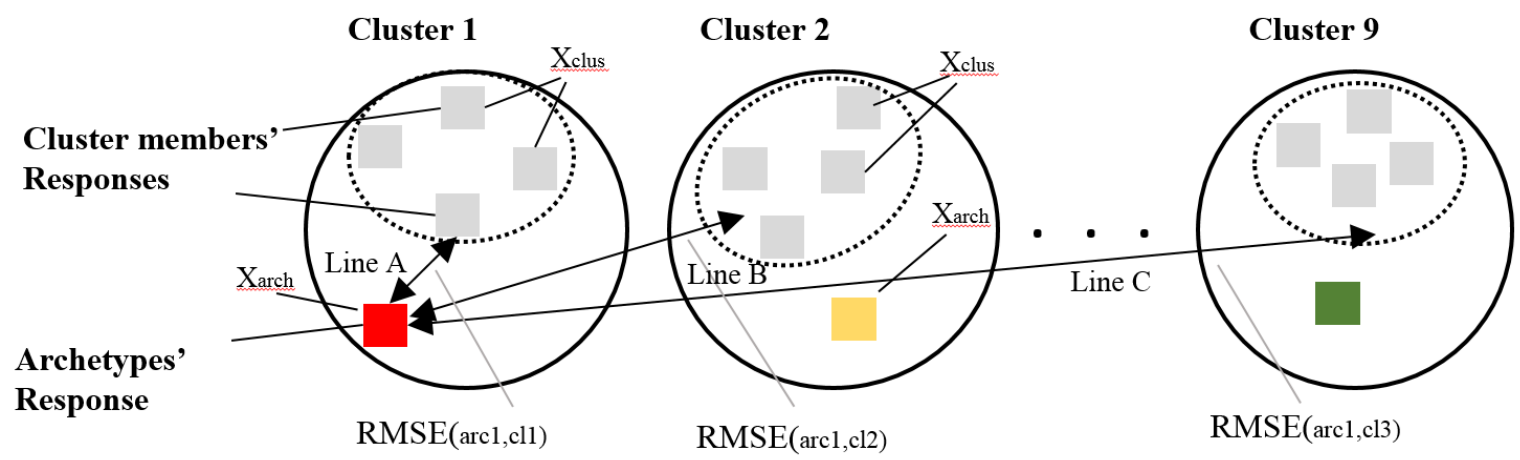

Figure 9. Example of assessment of closeness for Archetype 1

Figure 9 shows a schematic representation of the assessment of closeness for Archetype 1. The difference $\left(\mathrm{X}_{\text {clus }, i}-X_{\text {archl }}\right)$ was calculated for each cluster with $i$ representing the number of the cluster members' responses within each cluster. The squared root of the deviation of the difference was calculated between Archetype 1 and all 9 clusters, as described in the presented equation of the RMSE. The same process was repeated 9 times, in respect to the number of clusters, for the remaining Archetypes $2,3 \ldots, 9$. To prove the validity of the archetypes we would expect that Line A<Line B<Line C. Cluster groups are not based on a single measure but on a combination of measures (three critical dimensions). So in some values we would observe closeness but not a linear formation.The RMSE was calculated only for those cases where the archetype person and the cluster member interacted with the same product (out of the two possible used in the study) (See Figure 5). In total, 41 RMSE value were calculated. These are presented in the following table (see Table 3): 


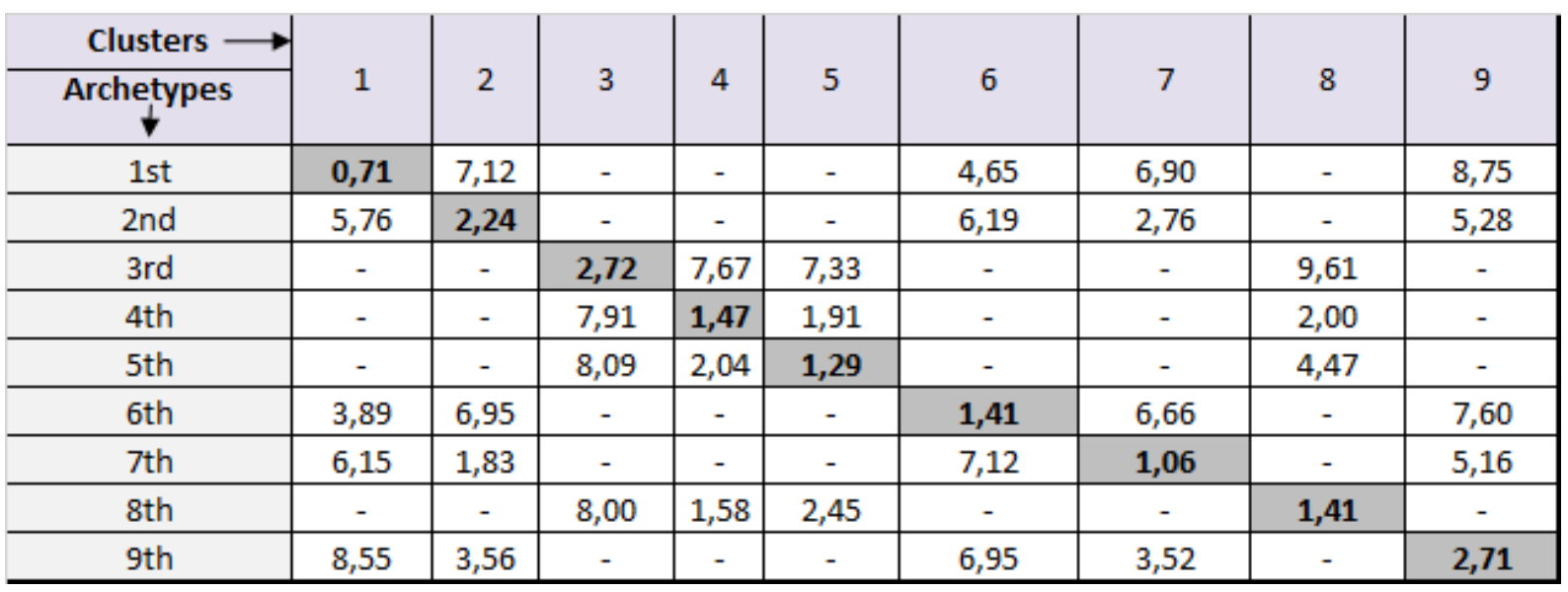

Table 3. Table of RMSEs for all 9 clusters

Table 3 clearly shows that the pairs on the diagonal line, (Archetype1, Cluster1), (Archetype2, Cluster2) ... (Archetype9, Cluster9) are the smallest values compared to the RMSE values in each of the lines in the table. Statistically, this translates to the fact that, the error between the predicted value and the cluster members' value is smaller within the archetype's cluster compared to the errors calculated between the archetype and the remaining clusters, hence, the archetype response is a better representation of its cluster than of any other of the remaining 8 clusters.

\subsection{Limitations}

Limitations for the two studies are presented in this section. Ear data of 200 people were collected, this is the minimum number to ensure that the population is sufficiently represented. Including more participants in the data collection will generate more reliable archetypes and further solidify the findings of the second study. Additionally, the selection of more critical ear dimensions would provide with more accurate archetypes. The acquirement of additional measurements around the ear canal area will improve the predictions of fit since these measurements are linked to the ear gels of the headsets, which is a crucial product component for high scores of physical comfort. A total of 9 archetypes were selected because of limitations in time and resources. There is, however the possibility to create more clusters, which will increase the number of archetypes, hence improve the understanding of the ear data and the prediction of physical comfort. Regarding the second study, although a sample size of 20 is sufficient to demonstrate the method, a larger number of participants would ensure that there is a significant number of participants distributed among the clusters. This is planned as part of further work in order to gain a better knowledge of the link between perception of physical comfort and anthropometry. Finally the choice of behind-the-ears products may have resulted in wider deviations due to the fact that the products may require a slightly different set of human factors, that is, a different set of anthropometric ear dimensions than the product (in-the-ear) that the dataset was collected from, which points to the need for more ear measurements needed to increase the applicability to a wider range of ear products.

\section{Conclusion}

In this paper, the ARCH method, another approach to develop a reliable user panel through using archetypes to represent clusters was developed and validated. ARCH was described, performed and validated. Anthropometric data from 200 participants was collected together with identification of critical dimensions for external-ear worn products. Cluster analysis was performed, and the participants were distributed into 9 clusters, and archetypes were generated to represent each cluster. The ARCH methodology was evaluated through analysis of 20 pariticpants' responses against the archetypes' responses during their interaction with in-the-ear and behind-the-ear products. Hence, the archetype's 
response to represent their cluster could be evaluated. The RMSe analysis showed that the archetypes' responses were close to their cluster members' responses, hence, validating the archetypes methodlogy. The methodological framework (the ARCH method) to develop a representative user panel for the execution of comfort studies in the ear industry was presented, i.e. a method to identify archetypes, summarizing the various steps of the process as they were presented in earlier sections of this paper.

The first contribution of the ARCH method identifies archetypes from cluster analysis on a large set of data, which can then be used to identify participants for a test panel. Although the initial data maybe cumbersome to collect the benefit of the approach is the identification of archetypes, reducing the number of participants, and that the method can be reused for other products. This method contributes in the reduction of cost and time as an alternative to statistical approach, which would require a large number of users (due to the ears' high geometric complexity). Moreover, the archetype methodology can be applied to other product families of external-ear devices as well as other products which are in physical contact with the human body (such as helmets, clothing, etc.) and provide with representative panels for user testing and the evaluation of prototypes. There, the same dataset can be reused with new clusters and generated archetypes depending on the selection of anthropometric measurements and critical dimensions.

The second contribution of this paper shows that through the study of the participants' responses versus the respective responses of the archetypes it was proved that certain aspects of physical comfort, such as the secure fit, can be predicted based on the knowledge of anthropometry and human factors. The anthropometric data can be a predictor of a participant's response of perceived (physical) comfort, hence by using the archetypes, the data of the archetypes can be used to predict the perceived response of other members of the cluster, i.e. reducing the need for qualitative studies.

The ARCH method has already been implemented in the industry of external-ear worn headsets, namely in the product category of in-the-ear headsets, with positive results for comfort and usability. These findings are of benefit to both designers and researchers by proposing an improved comfort methodology and a meaningful and faster way to design and test the comfort studies executed in the industry.

\section{Acknowledgements}

Research was carried out at the Technical Univeristy of Denmark. The authors would like to thank all participants for their contribution in the execution of the study.

Special thanks to Prof. Neil Mansfield for his valuable contribution in the analysis of data.

\section{References}

Bishu, R. R., M. S. Hallbeck, et al., "Seating comfort and its relationship to spinal profile: A pilot study", International Journal of Industrial Ergonomics, Vol. 8(1), 1981, pp 89-101

Chao, A., A. J. Kumar, et al. "An ergonomic evaluation of Cleco pliers.", 'Ergonomics for the New Millennium', 2000, pp 441-442

Cho, 1994, A. Cho, "Fitting the chair to the school child in Korea", Hard Facts About Soft Machines: The Ergonomics of safety, Taylor \& Francis, Vol. 24(2), 1994, pp. 279-288

Cochran WG (1977) Sampling Techniques, 3rd. ed.

De Looze, M. P., L. F. M. Kuijt-Evers, et al. "Sitting comfort and discomfort and the relationships with objective measures", Ergonomics, Vol. 46(10), 2003, pp 985-997

Ergonomics, Vol. 33 (12),1990, pp 1511-1521

Fellows, G. L. and A. Freivalds, "Ergonomics evaluation of a foam rubber grip for tool handles", Applied Ergonomics, Vol. 22(4), 1991, pp 225-230

Ghoddousi, H., R. Edler, et al., "Comparison of three methods of facial measurement.", International Journal of Oral and Maxillofacial Surgery, Vol. 36(3, 2007), pp 250-258.

Goossens, R.H.M., Teeuw, R. and Snijders, C.J., "Sensitivity for pressure difference on the ischial tuberosity." Ergonomics(submitted), 2002 
Habsburg, S. and L. Middendorf, "What really connects in sittin comfort? Em dash studies of correlates of static seat comfort", SAE Prepr (770247), 1977

Hennessy, R. J., A. Kinsella, et al., "3D laser surface scanning and geometric morphometric analysis of craniofacial shape as an index of cerebro-craniofacial morphogenesis: initial application to sexual dimorphism", Biological Psychiatry, Vol. 51(6), 2007, pp 507-514.

Hertzberg, H.T.E. Annotated Bibliography of applied physical anthropology in human engineering, Report No. WADC-TR-56-30, Wright-Patterson Air Force Base. OH: Aero-Medical library, 1958

Hibaru and Watanabe, "A procedure for allocating chairs to school children", Hard facts about soft machines, London, 1994

Jung Hwa S., Hyung-Shik Jung, Surveying the dimensions and characteristics of Korean ears for the ergonomic design of ear-related products, Received 23 May 2001

Jianghong, Z. and T. Long "An evaluation of comfort of a bus seat", Applied Ergonomics, Vol. 25(6), 1994, pp 386-392,

Kee, D. and I. Lee "Relationships between subjective and objective measures in assessing postural stresses", Applied Ergonomics, Vol 43(2), 2012, pp 277-282.

Klamklaya, , Angoon Sungkhaponga, Nantakrit Yodpijitb, Patrick E. Pattersonc, "Anthropometry of the southern Thai population”, International Journal of Industrial Ergonomics, Vol. 38(1),2008, pp 111-118

Kleeman, W., "The challenge of Interior design”, Boston, MA: CBI, 1981

Kuijt-Evers, L. F. M., L. Groenesteijn, et al., "Identifying factors of comfort in using hand tools", Applied Ergonomics, Vol.35, 2004, pp 453-458

M.K. Gouvali,K. Boudolos, "Match between school furniture dimensions and children's anthropometry”, Applied Ergonomics, Vol. 37(6), 2006, pp 765-773

Merllié, M. and Paoli, P. "Working Conditions in the European Union”, Dublin: European Foundation for the Improvement of Living and Working Conditions, 2002

Mououdi M.A., Choobineh A.R., "Static anthropometric characteristics of students age range six-11 in Mazandaran province/Iran and school furniture design based on ergonomics principles", Applied ergonomics, Vol. 28 (2), 1997, pp 145-147

Parcells et al., 1999, C. Parcells, M. Stommel, R.P. Hubbard, "Mismatch of classroom furniture and student body dimensions: empirical findings and health implications”, Health, Vol. 24 (4), 1999, pp. 265-273

Paul, R. D., "Nurturing and pampering paradigm for office ergonomics", Proceedings of the Human Factors and Ergonomics Society 1, 1997, pp 519-523

Richards, L. G. "On the psychology of passenger comfort", Human Factors in Transport Research, Vol. 2: User Factors: Comfort, The Environment and Behaviour, 1980, pp 15-23

Sanders and McCormick," Human Factors in Engineering and Design”, (seventh ed), M.S. Sanders and E.J. McCormick, McGraw-Hill, New York, 1993

Slater K. "Human Comfort (Book)." Contemporary Sociology 16(6), 1987

The Oxford Dictionary of English (2nd ed., rev. 2005)

Vink, P. and S. Hallbeck, 2012, "Comfort and discomfort studies demonstrate the need for a new model." Applied Ergonomics, Vol. 43 (2), pp 271-276

Vink, P., "Comfort and design: principles and good practice”, Boca Raton CRC Pres, 2005

Vink, P., Hark, T.A. and Krause, F., “Future Demands on Comfort in Construction Vehicles' Interiors”, 2001, according to Manufacturers, Hoofddorp: TNO Work and Employment

Weinberg, Naidoo, Govier, Martin, Kane, Marazita, "Anthropometric Precision and Accuracy of Digital ThreeDimensional Photogrammetry”, Journal of Craniofacial Surgery, Vol. 17(3), 2006, pp 477-483

Wilder, D., M. L. Magnusson, et al., "The effect of posture and seat suspension design on discomfort and back muscle fatigue during simulated truck driving", Applied Ergonomics, Vol. 25(2), 1994, pp 66-76

Zhang, L., M. G. Helander, et al., "Identifying factors of comfort and discomfort in sitting", Human Factors, Vol. 38(3), 1996, pp 377-389

Hyndman, Rob J. Koehler, Anne B.; Koehler "Another look at measures of forecast accuracy". International Journal of Forecasting, 2006,. Vol. 22 (4): 679-688.

Stavros - Konstantinos Stavrakos

Postdoctoral Research Associate,

Dyson School of Design Engineering,

Imperial College London,

London 
s.stavrakos@imperial.ac.uk 